point - anyone wishing to use these letters in other works of scholarship will have to go to their sources to find out this information, thus forcing a duplication of effort that could easily have been avoided.

While I agree that footnotes to letters should be as short and concise as possible, it is important that they also provide the information necessary for the reader to understand what he is reading. In too many letters, there are names which are not identified. When Alfred Sturtevant urges Milislav Demerec "to try and get hold of Pink Jesus (= Bug Forbes)"' (p.327), I suspect that few readers will understand the allusion. Professor Forbes was one of Cornell's legendary figures whose beard and ruddy complexion gave him his nickname and who certainly deserves a footnote. In other cases, a person is identified, if giving a first name, last name and dates of birth and death can be counted as identification - surely a brief description of a person's place in science would have been helpful? The Reingolds also do not always provide essential information for their readers about scientific matters. In the same letter from Sturtevant and the one immediately preceding it, Sturtevant mentions Oenothera lamarckiana. How many readers will immediately recognize this as the plant used by Hugo de Vries in his studies of mutation? The Reingolds say nothing.

Although these are serious criticisms, I would not like to close on a sour note. This is not an adequate documentary history of science in America, as its title insists; but it is a fascinating slice of scientific Americana that should prove both stimulating and useful to a wide variety of readers.

L. Pearce Williams is the John Stambaugh Professor of the History of Science at Cornell University. He is the author, among other works, of Michael Faraday, A Biography (Chapman \& Hall, 1965).

\title{
In terms of analytical chemistry
}

\section{T.S. West}

A Dictionary of Chromatography, 2nd Edn. By R.C. Denney. Pp.229. UK ISBN 0-333-31667-3; US ISBN 0-471-87477-9. (Macmillan Press/Wiley: 1982.) £15, \$39.95. A Dictionary of Spectroscopy, 2nd Edn. By R.C. Denney. Pp.205. UK ISBN 0-333-31670-3; US ISBN 0-471-87478-7. (Macmillan Press/Wiley: 1982.) £15, $\$ 39.95$.

THESE two second-edition dictionaries of chromatography and spectroscopy are attractive additions to the chemist's bookshelf, where they should serve as useful guides to those not fully expert in either technique. The author has successfully put together a reasonably comprehensive set of terms and definitions and has translated them into SI terminology in keeping with present-day trends. The terminology of the IUPAC "Orange Book" of Analytical Nomenclature has been adhered to fairly closely, and the author has steered a consistently sagacious path through the minefield of inconsistencies that abound in these as in most other areas of nomenclature.

I was, however, disappointed to find no mention of "limit of detection" in either book or "sensitivity" in the spectroscopy volume. Both volumes similarly define the term "signal-to-noise", but in neither is it said exactly what a signal is and the explanation of noise will not be very helpful to the puzzled novitiate, even in the chromatography volume. However, terms such as these are perhaps the most difficult to define and the author may have been wise to avoid or define them minimally. On the other hand, useful reference could certainly have been made to other terms such as "time-resolved spectra", and "'background", particularly for the newcomer to these techniques.

In both books the author has made excellent use of explanatory diagrams, 55 each for both chromatography and spectroscopy, and in general the definitions are clear and very much to the point, particularly those in the chromatography volume. Each book includes an extensive list of references for further reading, but a glossary of the terms defined, with the page numbers, would have been useful even though the two books are alphabetical lists from start to finish.

The chromatography volume gives the impression of being more comprehensive and perhaps more sure-footed than that on spectroscopy. However it may well be that the latter serves a more useful purpose in that it deals with some of the newer electron spectroscopies - such as Mössbauer and Auger spectroscopy - that are less well covered in other dictionaries which tend to concentrate exclusively on the more familiar molecular, atomic and electron spectroscopy techniques.

Each book is timely and excellent in conception, and in remarking that I would like to have seen such and such a term defined, I am basically expressing my satisfaction with the other definitions and wishing that there could have been more of the same. Both volumes deserve to sell well; they are especially recommended for student use.

T.S. West is Director of the Macaulay Institute for Soil Research, Craigiebuckler, Aberdeen.

\section{Integrated enzymes}

\section{Athel Cornish-Bowden}

Fundamentals of Enzymology. By N.C. Price and L. Stevens. Pp.454. Hbk ISBN 0-19-857175-5; pbk ISBN 0-19-857176-3. (Oxford University Press: 1982.) Hbk £25, $\$ 49$; pbk £12.50, $\$ 24.95$.

ENZYMOLOGY has a role in nearly all aspects of research in biochemistry, and is of central importance in the whole subject. Partly because of this, it is commonly taught to undergraduate students as a series of disconnected topics. The people who study protein structure often have little in common with those concerned with the control of metabolic processes in the living organism. A third group of people study enzyme kinetics, and among these there sometimes seems to be an unbridgeable gulf between those who are interested in the steady state and those who are interested in transients. Yet these and other aspects of enzymology are all part of the same subject and it is clearly desirable to integrate them.

The present book is an attempt to describe enzymology as a whole, from the structures and properties of isolated enzymes to their roles as components of complex metabolic systems. It is written at a level where it can easily be understood by undergraduates, but it has enough detail to be of value to any research worker with an interest in enzymes. It is not the first book to attempt such a synthesis, but it is easily the most successful that I have seen, and it deserves to become a standard textbook of general enzymology.

The book is informative and accurate about the aspects of the subject that I know best, and so I feel inclined to believe what it tells me when it ventures into less well known territory, for example (in a final chapter on enzyme technology) about the origin of the holes in Swiss cheese. I found few faults, none of them serious. Although the authors are not themselves confused about the distinction between the Hill coefficient and the number of binding sites on a protein, they may well confuse their readers because they use the same symbol for both quantities on nearly consecutive pages.

Although monstrosities such as SGOT make fleeting appearances (inevitable, perhaps, in a chapter on clinical enzymology), and molecular weights are mentioned throughout, the authors have in general made commendable efforts to refer to enzymes by their recommended names and to use modern units and terminology. Even the clinical chapter is largely written in English, perhaps the first time this has ever been achieved.

Athel Cornish-Bowden is a Lecturer in Biochemistry at the University of Birmingham $U K$, and author of Basic Mathematics for Biochemists (Chapman \& Hall/Methuen, 1981). 